\title{
Floods effects on rivers morphological changes application to the Medjerda River in Tunisia
}

\author{
Mohamed Gharbi ${ }^{1}$, Amel Soualmia ${ }^{1 *}$, Denis Dartus ${ }^{2}$, Lucien Masbernat ${ }^{2}$ \\ ${ }^{1}$ University of Carthage, National Institute of Agronomy of Tunisia, Laboratory of Water Science \& Technology, Tunis, Tunisia. \\ ${ }^{2}$ University of Toulouse, National Polytechnic Institute of Toulouse, Institute of Fluid Mechanics, Toulouse, France. \\ *Corresponding author. E-mail: amel.inat@hotmail.fr
}

\begin{abstract}
In Tunisia especially in the Medjerda watershed the recurring of floods becoming more remarkable. In order to limit this risk, several studies were performed to examine the Medjerda hydrodynamic. The analysis of results showed that the recurrences of floods at the Medjerda watershed is strongly related to the sediment transport phenomena. Initially, a one dimensional modelling was conducted in order to determine the sediment transport rate, and to visualize the river morphological changes during major floods. In continuity of this work, we will consider a two-dimensional model for predicting the amounts of materials transported by the Medjerda River. The goal is to visualize the Medjerda behaviour during extreme events and morphological changes occurred following the passage of the spectacular flood of January 2003. As a conclusion for this study, a comparative analysis was performed between 1D and 2D models results. The objective of these comparisons is to visualize the benefits and limitations of tested models. The analysis of the results demonstrate that $2 \mathrm{D}$ model is able to calculate the flow variation, sediment transport rates, and river morphological changes during extreme events for complicated natural domains with high accuracy comparing with 1D Model.
\end{abstract}

Keywords: Floods; Hydrodynamics; Sediment transport; Modelling; River morphology.

\section{INTRODUCTION}

Because it controls the essential element of life, fluvial hydraulic is one of the oldest sciences explored by human (Goutx and Ladreyt, 2001). Fluvial hydraulic is involved in the study of stream flows in natural or artificial open channels (Graf, 1984). It appears fundamental for the design, flow propagation, and river morphological changes. Nowadays, numerical modelling is one of the main tools used in the study of river hydrodynamics. Indeed, through the use of new available technologies, numerical modelling of flow and sediment transport in rivers is strongly improved over the last decades and has been widely applied as a major research tool to solve several river hydraulic problems $(\mathrm{Wu}, 2008)$. In this context, we consider a 2D numerical model for predicting morphological changes in the Medjerda River due to the sediments transport process (Gharbi et al., 2014a).

In fact, the construction of the Sidi Salem dam, introduced a remarkable morphological change of the river hydrodynamic, especially on the downstream side (Talbi et al., 2014). We notice a huge sediment deposition due in part to frequent moderate floods and the presence of hydraulic structure that promote the river bed modification, and therefore favours the occurrence of catastrophic floods (Soualmia et al., 2015). Various researches have been made confirmed that the floods problem in the Medjerda River is powerfully linked to sediment transport process. At first, a one dimensional modeling of sediment transport was performed; it allowed us to determine the quantities of sediments transported by the river, and their impacts on the river longitudinal profile. It appears clear, that the great amounts of materials transported by the river have a significant impact on the river morphology. These changes may promote floods, threaten, destabilize hydraulic structures and disrupt their operations (Soualmia and Gharbi, 2014). In a second step, this current research considers a two dimensional model using TELEMAC 2D code coupled with SISYPHE code for analyzing the hydrodynamic and sediment transport mechanisms and predicting their effects. The 2D hydraulic model includes a significant improvement in calculating the variation of hydraulic variables, and also the delineation of flood zones (Dusty, 2012). Whereas, the sediment transport model provides us about the river morphological changes occurred during extreme events. To conclude, a comparative study of the results of both $1 \mathrm{D}$ and $2 \mathrm{D}$ models will be conducted in order to determine the advantages and weaknesses of these models for predicting the sediment transport capacity.

\section{PRESENTATION OF THE STUDY AREA}

The Medjerda is a river in North Africa flowing from northeast Algeria through Tunisia before emptying into the Mediterranean Sea. It is the longest river of Tunisia with a length of $450 \mathrm{~km}$, and the only permanent river in the country (Rodier et al., 1981). Despite the relatively low rainfall in the Medjerda watershed during the autumn and spring, severe flooding can be observed during these seasons (Fig. 1). This is generally due to the attributes flows from Algeria.

For our study case, we opted for the middle valley of Medjerda, which was flooded at least three times in these last years (Rodier et al., 1981). We will pay a particular attention to the reach located between the two dams of Sidi Salem and Laâroussia (Gharbi and Soulamia, 2013). This reach is extended over a length of $85 \mathrm{~km}$; it is powered by three tributaries: Wadi Khaled and Wadi Siliana at the left bank, and Wadi Lahmar at the right bank (Fig.1).

The implementation of a 2D model for the total river seems too heavy to calculate the various parameters through the extent of the study area $(85 \mathrm{~km})$. It was then considered for our study case, a portion of about $20 \mathrm{~km}$ of the Medjerda from Sidi Salem dam until the first measurement station of Slouguia. 


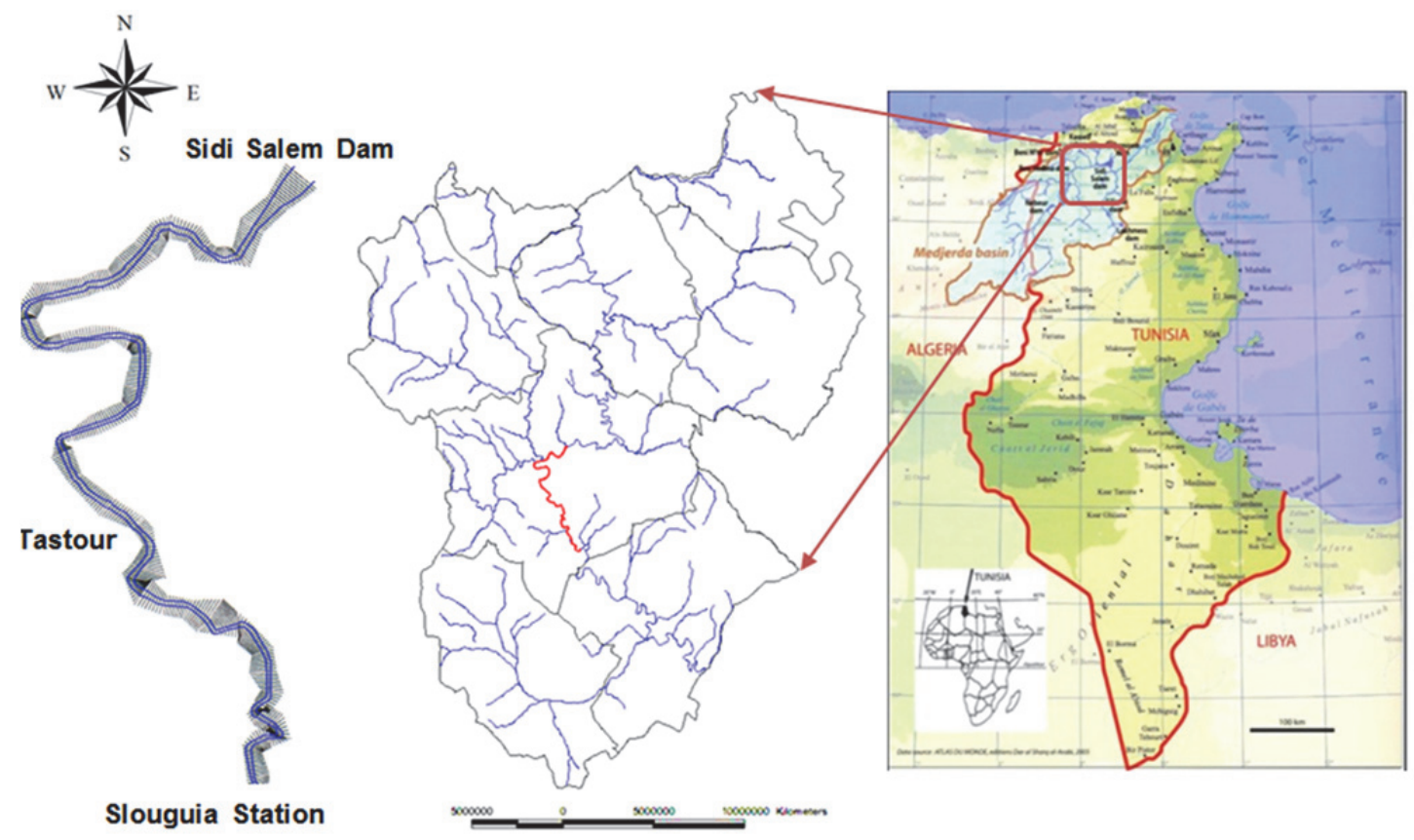

Fig. 1. Location of the study area: The middle valley of the Medjerda River, Tunisia.

\section{METHODOLOGY}

Floods can occur in rivers, reservoir, and coastal area with serious damage, when flow exceeds the capacity of the river channel. How to estimate and mitigate the risk of inundation is a crucial question now days (Zhang et al., 2014). The purpose is to determine the effects of major floods on river morphological changes. In fact, various numerical morphodynamic models are now being intensively used by the scientific community in order to predict morphological evolution in various complex applications (Belleudy, 2000). Most existing modelling systems offer a $1 \mathrm{D}, 2 \mathrm{D}$ or $3 \mathrm{D}$ version. The choice of the model dimension depends on the domain scale (Huybrechts et al., 2010). Considered as a great compromise, 2D modelling is widely applied to medium scale domains. In fact, the challenge of any modelling approach is to read the reality of the phenomenon through an adapted simplifying grid. Therefore, it has a great importance to find an eligible compromise between accuracy for the description of phenomena and the requirements of the model implementation (Diallo, 2010). A two dimensional model has been used for simulating the river bed evolution. The model consists of hydrodynamic equations, sedimentological equations and bed deformation equations (Zhang et al., 2014). The purpose of modelling in two dimensions is to complete and refine onedimensional modelling performed in a previous work (Gharbi and Soulamia, 2013). The first step is to collect or acquire all necessary data for the development of the hydraulic model, as well as its implementation. The data set (topographical and meteorological data) allows us to better understanding the hydrodynamic phenomena (Estupina et al., 2005). In a first step, we conducted a one dimensional modelling of sediment transport in the Medjerda using HEC RAS (1D) to determine the amount of sediment transport and its effects on the geomorphological evolution of the river longitudinal profiles. In continuity of this work, we used and adapted a complete 2D model for predicting the morphological evolution of the Medjerda. This type of model allows us to test various hypotheses of geomorphological dynamics; they also help us in identifying the various factors responsible for the river bed changes (Richards et al., 2002). This work considers the modelling of a real case; the chosen study area is the middle valley of the Medjerda River. But, to avoid problems calculations, we limited our study area to a portion of about $20 \mathrm{~km}$, from the Sidi Salem dam until the station Slouguia. This portion of the Medjerda is characterized by erosion during extreme events, and deposition during low flow periods. For that, we have chosen the TELEMAC 2D code coupled with the SISYPHE code for modelling the hydrodynamic and sediment transport process.

\section{DESCRIPTION OF THE USED MODELS}

Rivers modeling is a difficult task because the flow in open channels is usually turbulent, the geometry is irregular, and can vary with time, and the accompanied sediment transport phenomena are complex (Wu et al., 2000). The choice of a specific model depends on the nature of the problem (Huybrechts et al., 2010). According to the method of calculation, there are totally decoupled models, semi-coupled or fully coupled (Wu, 2008). The fully decoupled models ignore the influence of sediment transport and bottom changes on flow fields, and calculate hydraulic parameters and sediment transport rates separately at each time step. However, the fully coupled models take into account the channel morphological changes for calculating the various flow parameters (Tassi and Villaret, 2014). Furthermore, in terms of numerical method, flow patterns and sediment transport can use the method of finite differences, finite volumes, and finite elements. Each of these numerical methods has its advantages and disadvantages (Fig.2).

TELEMAC 2D is an ideal modeling framework for rivers due to its finite element grids which allow graded mesh resolution (Hervouet, 2007). In fact, areas that require high bathymetric accuracy such as meandering can be well resolved by TELEMAC 2D. This model performs 2D hydraulic calculations; it solves Saint-Venant equations of momentum and continuity, derived from the Navier-Stokes equations by taking the vertical average. The main results give the water depth and the average vertical velocity at each point of the resolution mesh (Villaret and Hervouet, 2006). 


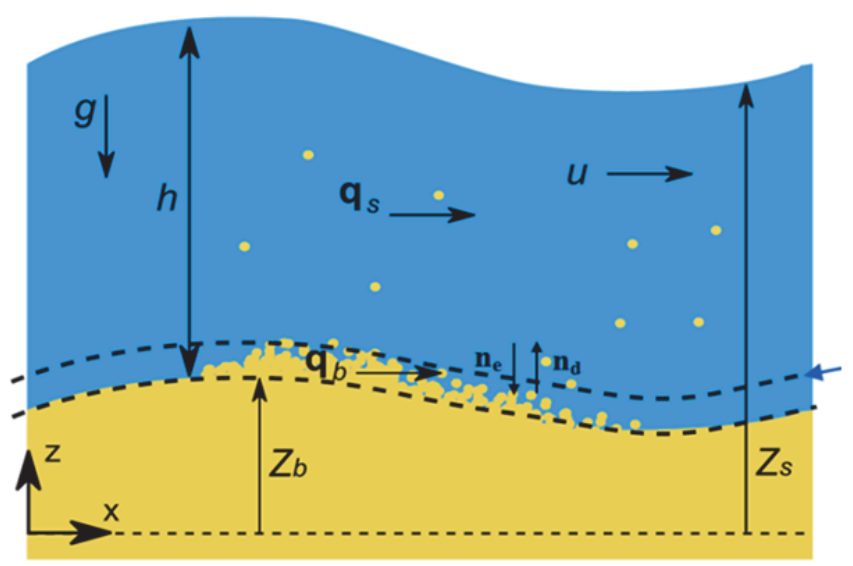

Fig. 2. Flow configuration.

SISYPHE is the state of the art sediment transport and bed evolution module of the TELEMAC modeling system. SISYPHE can be used to model complex morphodynamic processes in diverse environments, such as coastal, rivers, lakes and estuaries, for different flow rates, sediment size classes and sediment transport modes (Tassi and Villaret, 2014). In SISYPHE, sediment transport processes are grouped as bed load, suspended load or total load, with an extensive library of bed load transport relations. SISYPHE is open source software; it is a horizontal two dimensional morphodynamic model. SISYPHE can be internally coupled to the module TELEMAC 2D, in order to take in account the evolution of the bottom in calculating hydraulic parameters (Fig.3).

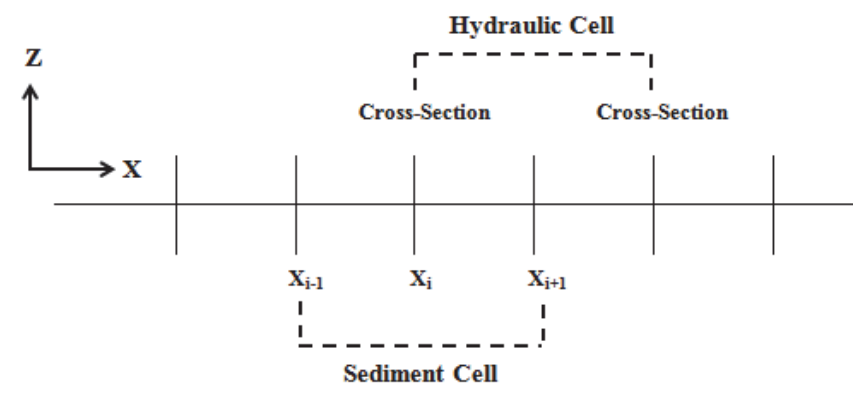

Fig. 3. Example of information exchange for coupling hydraulic and sediment transport models.

For the evaluation of sediment transport rates, unlike the usual models which take into account only one median diameter, SISYPHE provides a non-uniform pattern (multiple-size). These non-uniform sediment models are based on a complicated sedimentary description considering several size fractions very close to reality. In fact, building a model under SISYPHE requires the definition of hydraulic and sedimentary conditions. It's noted that we need to use several tools to create the various files required to build the model under TELEMAC 2D and SISYPHE.

\section{The 2D hydraulic model}

The flood flow in river was described for the first time by Saint-Venant in 1871 . In many problems of river hydrodynamic, the flow varies slightly in the vertical direction so that the consideration of the equations in two dimensions can solve the problem. In fact, from Navier-Stokes (3D) to Saint-Venant
(2D) it is assumed that vertical velocities are almost zero and the variables can be integrated vertically (Roche et al., 2012). The hydrodynamic models based on the full set of 2D SaintVenant equations are as follows:

$$
\frac{\partial h}{\partial t}+\frac{\partial(h u)}{\partial x}+\frac{\partial(h v)}{\partial y}=0
$$

$\frac{\partial(h u)}{\partial t}+\frac{\partial\left(h u^{2}\right)}{\partial x}+\frac{\partial(h u v)}{\partial y}=-h g \frac{\partial Z_{s}}{\partial x}+\frac{\tau_{x x}}{\rho}+F_{x}$

$\frac{\partial(h v)}{\partial t}+\frac{\partial(h u v)}{\partial x}+\frac{\partial\left(h v^{2}\right)}{\partial y}=-g h \frac{\partial Z_{s}}{\partial y}+\frac{\tau_{y y}}{\rho}+F_{y}$

where $x$ and $y$ are the horizontal Cartesian coordinates; $h$ is the water depth; $u$ and $v$ are the depth-averaged flow velocities in $x$ and $y$ directions; $Z_{s}$ is the water surface elevation; $g$ is the gravitational acceleration; $\rho$ is the density of water; $\tau_{x x}$ and $\tau_{y y}$ are the depth-averaged turbulent stresses, $F_{x}$ and $F_{y}$ are the Coriolis forces (Wu et al., 2000). The turbulent stresses $\tau_{i j}$ are calculated with the classical $k$ - $\varepsilon$ turbulence model (Rodi, 1984) which employs the eddy viscosity.

$\tau_{i j}=v_{t}\left(\frac{\partial u_{i}}{\partial x_{j}}\right) \quad \mathrm{i}=1,2 \quad \mathrm{j}=1,2$

where $\quad v_{t}=\frac{C_{\mu} k^{2}}{\varepsilon}$

where: $k$ is the turbulent kinetic energy; $\varepsilon$ is dissipation rate; $v_{t}$ is the eddy viscosity.

\section{The 2D sediment transport model}

In SISYPHE, there are two sediment transport modes according to the transport mechanisms, the bed load and the suspended load:

$$
q_{t}=q_{b}+q_{s}
$$

where $q_{t}$ is the total sediment transport, $q_{\mathrm{b}}$ is the bed load transport, and $q_{s}$ is the suspended transport.

Evaluation of sediment transport is one of the most important tasks in river hydraulics. In this context, several works since more than twenty years in the world have helped to solve many problems encountered in rivers, especially the development of sediment transport models (Van Rijn, 1993). The twodimensional (2D) sediment transport equation for the depthaveraged suspended load concentration $c$, is obtained by integrating the $3 \mathrm{D}$ sediment transport equation over the suspended load zone ( $\mathrm{Wu}, 2008)$. The two-dimensional transport equation is given by:

$$
\frac{\partial c}{\partial t}+u \frac{\partial c}{\partial x}+v \frac{\partial c}{\partial y}=\frac{\partial}{\partial x}\left(\varepsilon_{s} \frac{\partial c}{\partial x}\right)+\frac{\partial}{\partial y}\left(\varepsilon_{s} \frac{\partial c}{\partial y}\right)+\frac{\dot{n}_{e}-\dot{n}_{d}}{h}
$$

where $c$ is the local sediment concentration; $\varepsilon_{s}$ is the dissipation rate; $\dot{n}_{e}$ and $\dot{n}_{d}$ are the width averaged sediment entrainment and deposition fluxes at the interface between the suspended load and bed load zones. For the calculation of suspended sediment 
transport rate, SISYPHE uses the finite elements method to numerically solve the (Eq. 7). Second, for the bed evolution, SISYPHE solves the Exner equation given by:

$(1-p) \frac{\partial Z_{b}}{\partial t}+\frac{\partial\left(\delta_{b} c_{b}\right)}{\partial t}+\frac{\partial\left(q_{t, x}\right)}{\partial x}+\frac{\partial\left(q_{t, y}\right)}{\partial y}+\dot{n}_{e}-\dot{n}_{d}=0$

where $Z_{b}$ is the bed elevation; $\mathrm{p}$ is the bed porosity ( $p \sim 0.4$ for non-cohesive sediment); $c_{b}$ is the sediment concentration in the bed load layer.

Concerning the erosion and deposition rates, representing the vertical flow of materials, exchanged between the bed load and suspended layer, they are involved in both the development funds equation as well as in the trans-diffusion equation. To calculate the erosion and deposition rates, SISYPHE provides various empirical laws. Several empirical laws have been proposed, following Celik and Rodi (Celik and Rodi, 1988), they introduce the equilibrium concentration, denoted $c_{e q}$, which represents the concentration obtained at the interface located at $z=Z_{\text {ref }}$, when saturation is reached. The erosion and deposition terms are given by:

$\dot{n}_{d}=V_{s} \cdot c_{r e f}$

and

$\dot{n}_{e}=V_{s} \cdot c_{e q}$

where $c_{e q}$ is the equilibrium concentration, $c_{r e f}$ is the reference concentration, and $\mathrm{V}_{\mathrm{s}}$ is the settling velocity.

Whereas, calculating the bed load transport rate, SISYPHE provides several empirical bed load model. Below we present the most used empirical laws for calculating the bed load transport rate (Table 1).

Where $\tau^{*}$ is the Shields number, $\tau_{c}^{*}$ is the Critical Shields number, $S$ is the bed slope, $T$ is non-dimensional excess bed shear stress; $K$ is the Einstein coefficient; $D_{50}$ is the median sediment diameter; and $D_{*}$ is the dimensionless particle size, $\rho_{\mathrm{s}}$ is the sediment density; $\rho$ is the water density, $R$ is the relative density (Shields, 1936). The $D *$ and $T$ parameters are given by the following equation:
$D_{*}=D_{50}\left(\frac{\left(\rho_{s}-\rho\right) g}{\rho v_{t}^{2}}\right)^{1 / 3}$

and $T=\frac{\left(\left(u_{*}\right)^{2}-\left(u_{*} c r\right)^{2}\right)}{\left(u_{*} r r\right)^{2}}$

where $u *$ is the bed shear velocity related to the grain; and $u_{*_{c r}}$ is the critical bed shear velocity for sediment motion.

For our case study, several simulations were made by various empirical laws of the literature. In fact, there are many laws proposed to quantify the bed load rate. Charru et al. (2004) proposed a new approach to study rivers morphological evolution. It is based on a model for the erosion and deposition of the particles under laminar flow. In 2006, Charru proposed an extension of this model to turbulent flow (Charru, 2006). In more advanced research Lajeunesse et al. (2010), realized an experimental study to support the erosion deposition model of Charru (2006), and proposed a new formula to calculate the bed load transport rate. Therefore, our objective is to test this new Lajeunesse formula for predicting the bed load rate transported by the Medjerda River during the flood of January 2003 (Lajeunesse et al., 2010).

\section{MODEL SET-UP}

For the implementation of 2D model, we opted for TELEMAC 2D coupled with SISYPHE for calculating both hydraulic parameters and sediment transport rate (Gharbi et al., $2014 \mathrm{~b}$ ). In fact when there is an overflow, there is no longer a preferred axis of flow, as should be the case in one-dimensional modelling (longitudinal axis). This imposes us to move to a two-dimensional modelling, using on the same assumptions, except that of the preferred axis of flow, and based on the twodimensional Saint-Venant equations. The two-dimensional hydrodynamic modelling is a tool for the representation of the evolution of flows during an event. The purpose of modelling in two dimensions is to complete and refine one-dimensional modelling performed in a previous work (Gharbi and Soulamia, 2013). So first, the topographic data (cross sections, the slope map, digital elevation model) are collected from the topo-

Table 1. Most commonly used formulas to describe bed load transport in a turbulent flow (Garcia, 2006).

\begin{tabular}{|c|c|}
\hline Authors & Formulas \\
\hline Meyer Peter (1948) & $q_{b}^{*}=8\left(\tau^{*}-\tau_{c}^{*}\right)^{\frac{3}{2}}$ \\
\hline Einstein (1950) & $q_{b}^{*}= \begin{cases}\frac{K \exp \left(-0.391 / \tau^{*}\right)}{0.465} & \text { si } \tau^{*}<0.182 \\
40 K \tau^{* 3} & \text { si } \tau^{*} \geq 0.182\end{cases}$ \\
\hline Van Rijn (1984) & $q_{b}^{*}= \begin{cases}0.053(R-1)^{0.5} g^{0.5} D_{50}^{1.5} D_{*}^{-0.3} T^{1.5} & T<3 \\
0.1(R-1)^{0.5} g^{0.5} D_{50}^{1.5} D_{*}^{-0.3} T^{1.5} & T>3\end{cases}$ \\
\hline Engelund (1976) & $q_{b}^{*}=18.74\left(\tau^{*}-\tau_{c}^{*}\right)\left(\sqrt{\tau^{*}}-0.7 \sqrt{\tau_{c}^{*}}\right)$ \\
\hline Recking (2010) & $q_{b}^{*}= \begin{cases}0.00005\left(\frac{\tau^{*}}{\tau_{c}^{*}}\right)^{12.9} & \text { for } \tau^{*} / \tau_{c}^{*}<2.11 S^{0.066} \\
14 \tau^{* 2.5} & \text { for } \tau^{*} / \tau_{c}^{*}<2.11 S^{0.066}\end{cases}$ \\
\hline Lajeunesse (2010) & $q_{b}^{*}=10.6\left(\tau^{*}-\tau_{c}^{*}\right)\left(\sqrt{\tau^{*}}-\sqrt{\tau_{c}^{*}}+0.025\right)$ \\
\hline
\end{tabular}




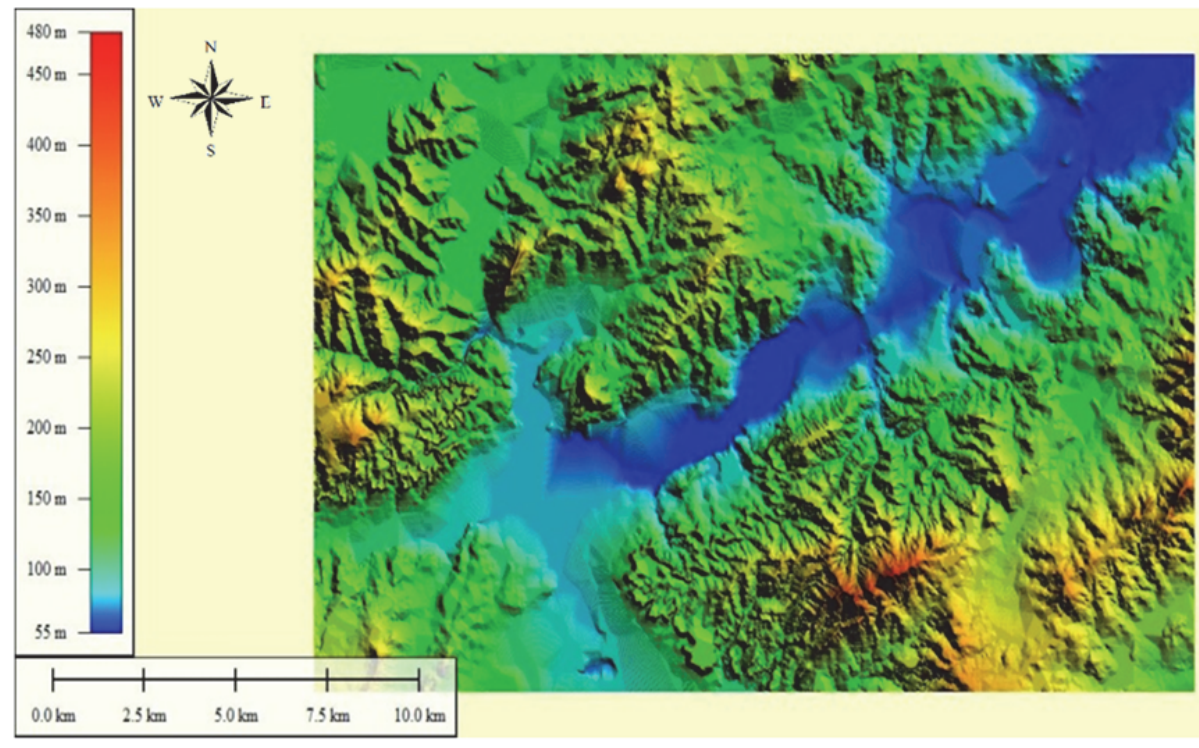

Fig. 4. Digital Elevation Model of the middle valley of the Medjerda River, Tunisia.

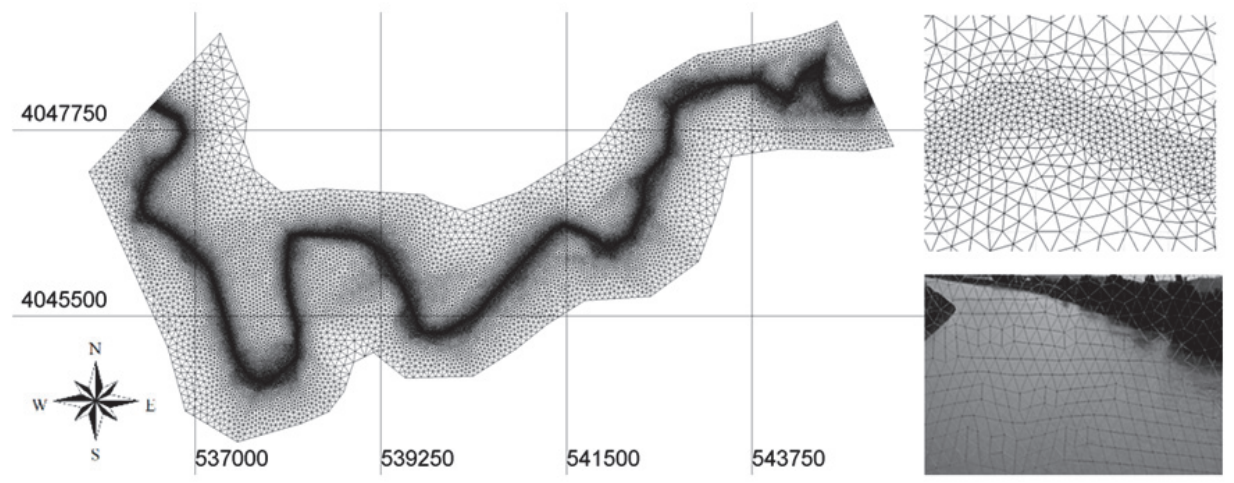

Fig. 5. Bathymetry of the middle valley of the Medjerda River, Tunisia, Flood 2003.

graphical campaign realized in 2003 by the Ministry of Agriculture and Water Resources (Gharbi and Soualmia, 2012). We present below the digital elevation model that we had established from assembling the topographic maps 1:25000 where the contours are $5 \mathrm{~m}$ spaced (high accuracy) (Fig. 4).

The definition of the geometry of river channels is a fundamental step. The river topography and hydraulic structures have a major impact on the simulated results. This step requires a good knowledge of areas and flows in order to consider all the existing hydraulic structures while simplifying the topography, to limit the number of calculation points (Rodi, 1984). In 2D models, the mesh provides information about the river topography. This kind of information is used to define precisely the area topography (Gharbi et al., 2014a). Thus, it is certain that more we have high accuracy data; more we can get model estimation closer to reality. In addition to successfully validate our mesh, we have refined it at the river bed. It was therefore considered triangular meshes of about $7 \mathrm{~m}$ to obtain maximum accuracy in the results. Then, we imposed a lighter mesh of about $50 \mathrm{~m}$ in the major bed, while to the rest of the field we imposed a criterion of $200 \mathrm{~m}$. At the end, we get a geometry file for simulation in 2D TELEMAC containing 51145 nodes (Fig. 5).

A first calculation with the hydraulic model TELEMAC 2D was conducted in order to determine the variations of hydraulic parameters during floods. The hydraulic model was calibrated based on the data sets measured during the flood in January 2003. For the modeling of sediment transport in the Medjerda, we followed a gradual approach in several stages. Initially, it was considered the sediment transport problem in a simple case. So we first examined the implementation of a onedimensional modeling of sediment transport, the study showed that Medjerda carries huge amounts of sediments. It is noted that if the river is too long, 1D numerical model are very useful; they provide the evolution over time of longitudinal profiles. However, in the case where we need to predict in more details the morphodynamical process in presence of complex flow conditions, 2D or 3D digital models may satisfy this need. Secondly, attention will focus on the implementation of a 2D modeling of sediment transport in the considered study area. We will therefore assume that the vertical variations of flow and sediment are small enough; variations in the horizontal plane can be described by Saint-Venant equations. Solving these equations by TELEMAC 2D module is performed on a mobile bed, where the bottom evolution is calculated by the SISYPHE module. The times and distances should be sufficient for the moving particles can be considered as a continuous mass (Recking, 2013).

For our case study, we dispose of the necessary information for the model implementation to quantify the materials 
transported by rivers. Below, we present the various available data for the implementation of a $2 \mathrm{D}$ model for the calculation of sediment transport rate; in fact, we need granulometric curve, rating curve, water depth, and flood hydrographs. It should be noted that all measurements were made directly in the Medjerda River. The grain size distribution of sediments in the Medjerda River is obtained by a sampling companion, where sediments were collected at several stations.

The particle size analysis is obtained by the technique of sieving and sedimentation in the laboratory of the General Directorate of Water Resources (DGRE). The available data set provides information about the particles diameter repartition of deposit samples. All these information are required for the analysis of sediment distribution in river. The granulometric fraction transported by the flows is composed essentially of clay and fine silt $66 \%$ at Slouguia, with a predominance of fine silt of about $35 \%$ at the Slouguia station.

\section{RESULTS AND DISCUSSION}

Let us summarize our results concerning the modeling of the Medjerda River performed by TELEMAC 2D coupled with SISYPHE. Initially, we started by the model calibration by adjusting the friction coefficient to approximate the measured data. However the Strickler coefficient is about $K s=25 \mathrm{~m}^{1 / 3} / \mathrm{s}$, it is deemed satisfactory because it corresponds to a river with abundant vegetation. We also present the evolution of sediment transport rate carried by the Medjerda. We were interested on the study of the morphological changes occurred after the passage of the spectacular flood of January 2003. The last part is dedicated to a comparative study between simulated results of 1D and 2D models. The aim is to determine the benefits and limitations of the 1D and 2D models, and to propose eventually the most suitable software for accurate modeling for the Medjerda River.

\section{General characteristics of the flow}

The first part of this paper focuses on the study flow parameters evolution simulated by TELEMAC 2D during the flood of January of 2003. The hydraulic model leads to define the variations of different hydraulic parameters including flow, velocity fields and the water depth (Masbernat et al., 2013). The analysis shows the presence of low speed area, and some high speed area depending on the bathymetry. We presents below the water levels predicted by the different models during the flood of January 2003 at the Slouguia station (Fig. 6).

Above all, the model calibration was based on the coefficient of Strickler ' $K s$ ' which has been adjusted to represent the role of the bottom nature (gravel, sand, silt...) and the land use (urban, forests ...) on flow dynamics (Thibault, 2013). The Strickler parameter has a great influence on the water level variation in rivers. Several simulation tests were carried out, by varying roughness. At the end of calibration, we note that predicted and measured hydrographs were also in good agreement. We retained $K_{s}=25 \mathrm{~m}^{1 / 3} / \mathrm{s}$, which represents relatively a high roughness. In fact, this may be justified by the dominance of vegetation in the banks and the bed River. We calculate the Nash criterion in order to evaluate the reliability of the different tested models. We got a Nash criterion of about 0.89 for TELEMAC 2D, and about 0.83 for HEC RAS (1D). Generally the different results are satisfactory; the Nash criterion is very close to 1 .

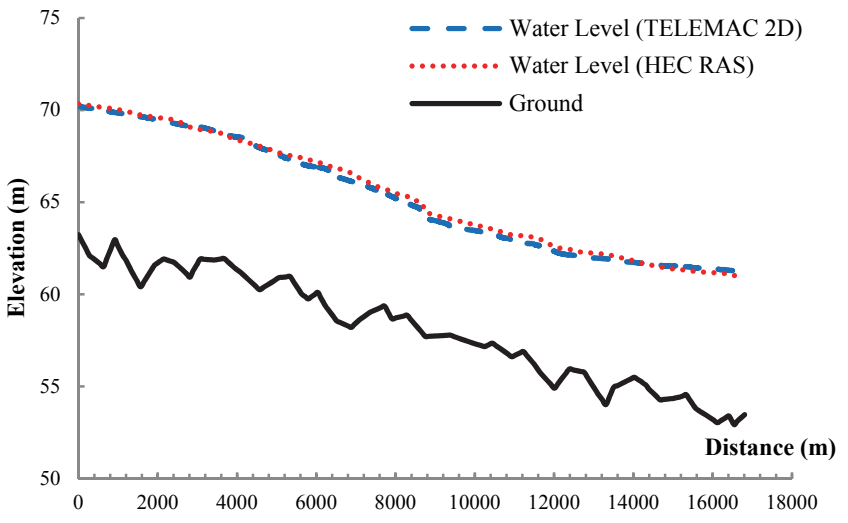

Fig. 6. Comparison between simulated water levels profiles along the Medjerda River during the Flood 2003 by TELEMAC 2D and HEC RAS (1D).

\section{Evolution of sediment transport}

During extreme events, the Medjerda transports huge amounts of sediment as either bed load or suspended load. The aim of this paper is to predict the sediment transport rate evolution in the river during the spectacular flood occurred in January 2003. We were also interested in calculating the amounts of sediments transport during floods, and to determine the dominant mode of transport of the Medjerda. In the following, in the first step we present the evolution of sediment transport rates along the river at different periods, in the second step, we will be interested in the study of the sediment transport variation at the Slouguia station.

\section{Evolution of sediment transport rate along the river}

We present below the variation of sediment transport over time. For different times during the flood of January 2003, we present below the evolution of the total sediment transport at the Slouguia station (Fig. 7).

Sediment discharge peaked just after the peak recorded at the flood hydrograph measured during the flood of 2003; this confirms the effect of fluid flow on the amount of sediment carried by the river. During the flood of 2003, a maximum liquid flow rate was recorded reaching $731 \mathrm{~m}^{3} / \mathrm{s}$ and corresponding to a sediment transport rate of about $4 \mathrm{~kg} / \mathrm{s}$. We also note that during floods, the dominant mode of materials transportation is the suspended load which represents of about $80 \%$ of the total sediment transport rate.

\section{Tests of different bed load Models}

Several simulations tests were performed in order to test the Lajeunesse formula cited above for predicting of the bed load rate (Gharbi et al., 2014a). We present below the calculated amounts of bed load by various models (Fig. 8).

The analysis indicates that the proposed model of Lajeunesse gives satisfactory results. The simulated bed load rates are closely correlated. To determine the degree of correlation between simulated results, therefore we calculated the correlation coefficient between simulated results. The analysis of results shows a correlation of about $71.1 \%$ between Lajeunesse and Van Rijn models and about $62.6 \%$ between Lajeunesse and Einstein models (Einstein, 1950; Engelund and Fredsoe, 1976; Lajeunesse et al., 2010; Meyer-Peter and Müller, 1948; Van Rijn, 1993). 


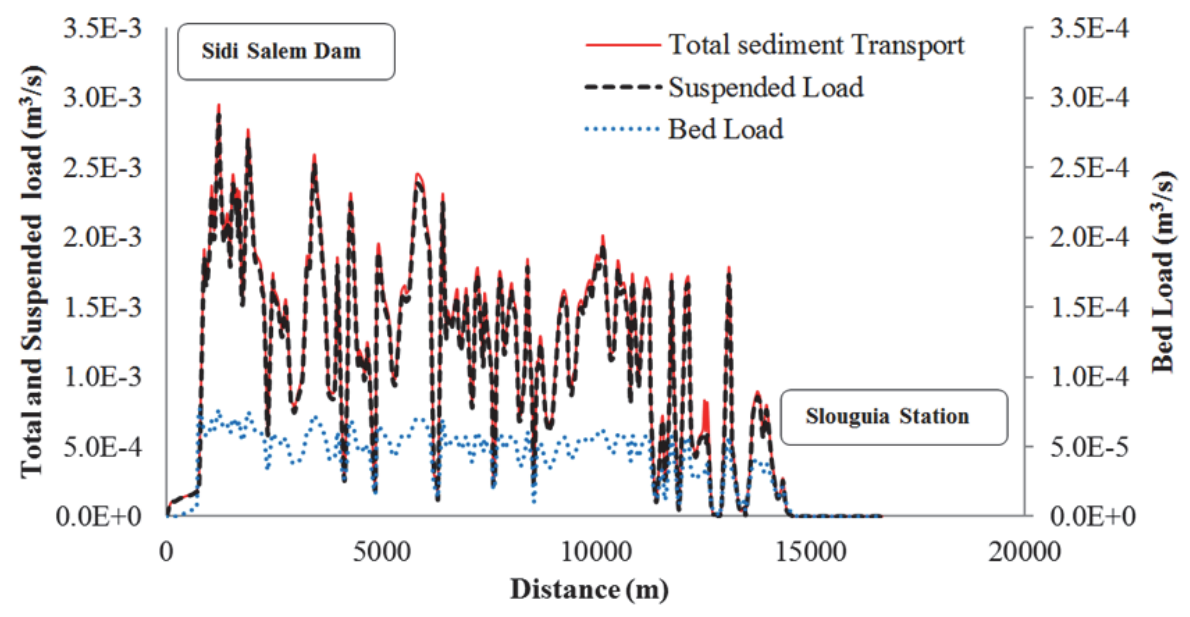

Fig. 7. Evolution of Suspended, Bed Load and Total Sediment transport along the middle valley of the Medjerda River, Flood 2003, TELEMAC 2D-SISYPHE.

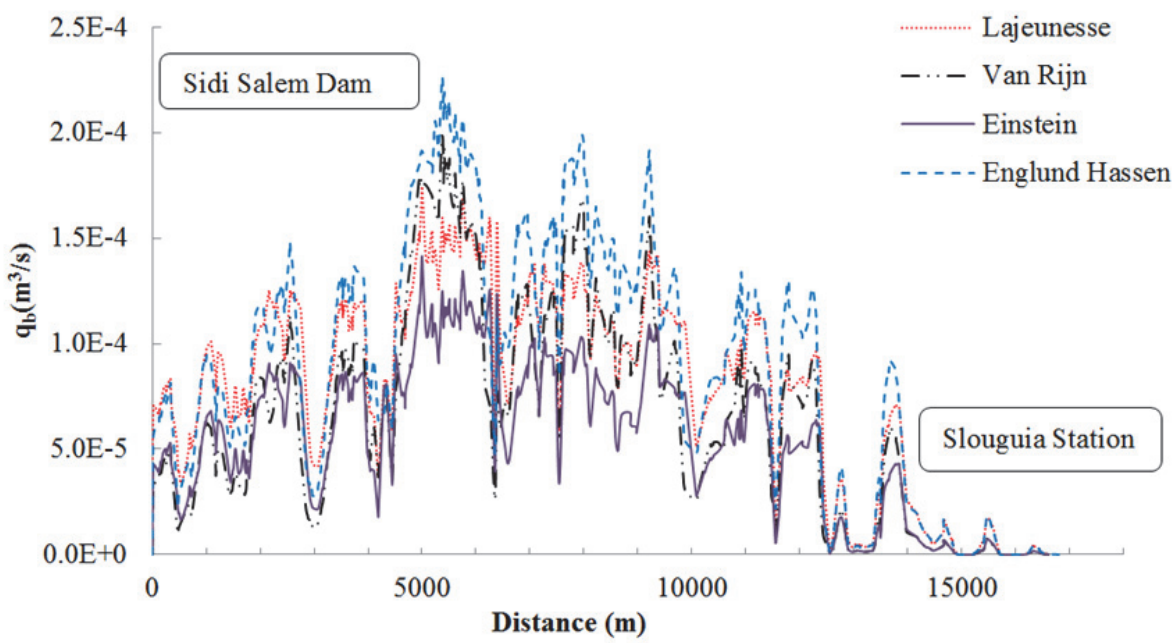

Fig. 8. Simulations of the bed load rate along the middle valley of the Medjerda River by different literature formulas, TELEMAC $2 \mathrm{D}-$ SISYPHE.

\section{Morphological evolution of the Medjerda River}

Channel processes reflected in river morphology are erosion, transportation and sedimentation. Erosion is the transport of sediments. Agents of erosion include flowing water, waves, wind, ice, or gravity. Eroded material is eventually dropped somewhere else; this is called deposition. The study reach is a one-kilometer stretch of the Medjerda River located just outside the dam. We present here the bathymetry evolution during the flood of 2003 (Fig. 9).

The analysis shows that there is a digging in the channel bottom reaching an average depth of $20 \mathrm{~cm}$. In fact during flood, there is always an alternation between the two processes of erosion and deposition, but given the important flow rates recorded at the outlet of the dam, the erosion process is dominant. Indeed, in the presence of hydraulic structures, the channel pattern of a river may be changed from braided to split, and may tend to become more sinuous (Williams and Wolman, 1984).

In fact by reducing the magnitude of frequent, moderate floods, dams may lead to channel narrowing through lateral accretion (Bhattacharyya, 2011). For that reason, we were interested in the study of the Medjerda morphological changes occurred after the passage of major flood. First, we will examine the morphological evolution of sets of cross-sections. Second, we control the longitudinal profile changes. The purpose is to localize deposition or erosion areas.

\section{Morphological evolution of cross sections}

The movement of sediment shows profound significance to river (Zhang et al., 2014). The process of sediment transport may change the topography of the river bed (Garcia, 2006). And the two processes of erosion and deposition are the key factor to control the river development and management. Erosion and deposition are responsible for many landforms, on the periods of low water level; the river promotes the deposition of sediment which causes a modification on the cross-section, directly related to the phenomenon of flooding. Whereas in times of flood, the phenomenon of erosion is favored due to the significant flow recorded during the flood, causing changes on the river morphology. The objective of this section is to analyze 


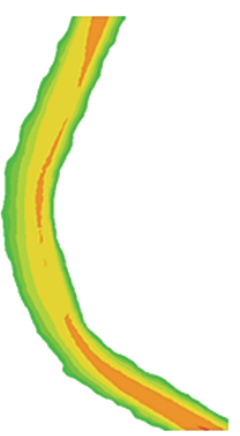

(a)

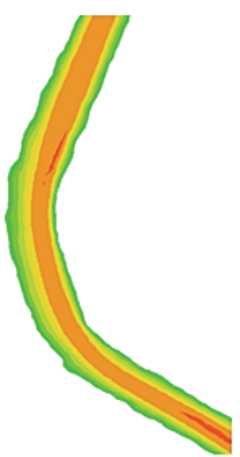

(b)

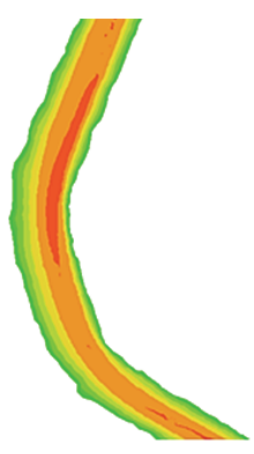

(c)

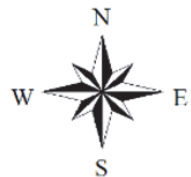

Bathymetry

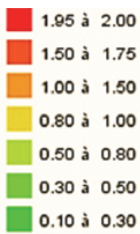

0.10 : 0.30

Fig. 9. Geomorphological evolution of longitudinal river profiles during flood of January 2003 in the Medjerda River (1 kilometer reach), TELEMAC 2D-SISYPHE.

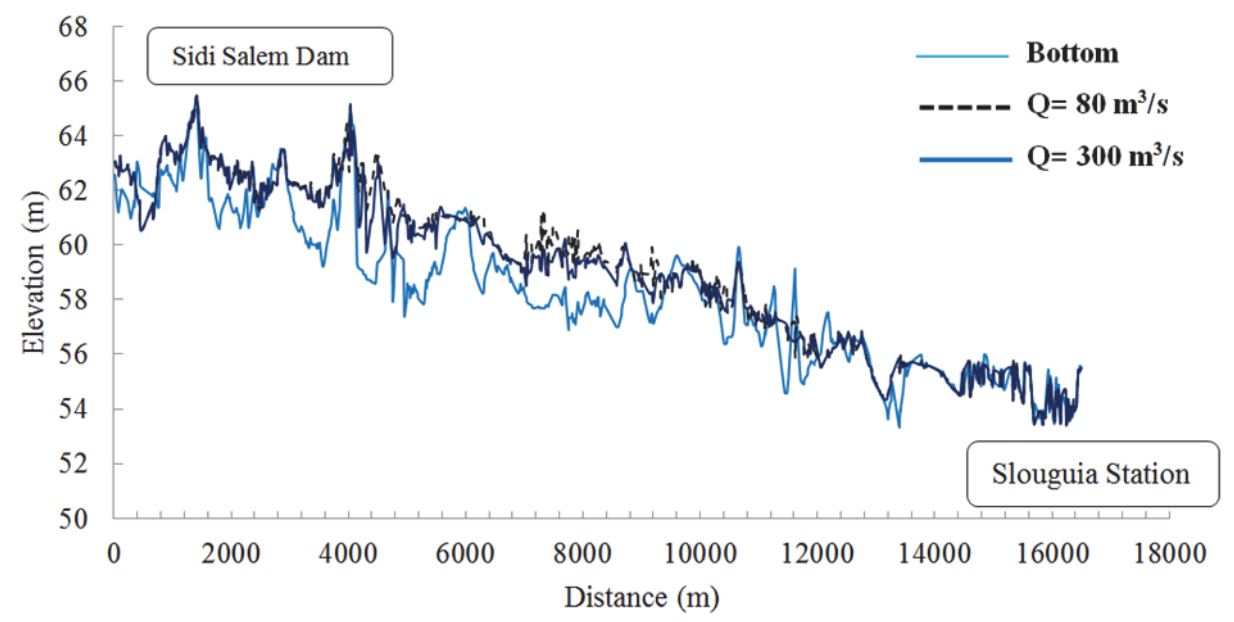

Fig. 10. Comparison between several cross sections during the Flood of 2003 predicted by TELEMAC 2D-SISYPHE.

the morphological evolution of some cross sections. A comparative analysis of several cross sections was conducted before and after the passage of the flood of 2003. The superposition of the cross sections at the same zone indicates silted sections (deposition zone) and erosion sections (digging in the bottom). The Figure 10 below provides information about various cross sections changes during the flood of 2003 (Fig. 10).

The used model for calculating particles size variation provides information about the solid mass transported by the river. This solid mass is directly translated into sediment volume; and this tells us about the morphological changes on river crosssections. The analysis of results shows several changes in both bed and banks of the river. The Slouguia Station is located about $20 \mathrm{~km}$ of the downstream of Sidi Salem dam. The analysis of the morphological evolution of set of cross sections shows that there is an alternation between the two processes of erosion and deposition.

\section{Longitudinal profiles changes in Medjerda}

Several studies have shown the important effects of flow rate on the sediment transport rate evolution. These studies have confirmed that the low flow does not modify the river morphology during 25 days (Goff and Ashmore, 1994). Conversely flood flows affect the river bed. In fact, from the first comparative analysis performed between sets of cross sections; we note that changes in cross sections are not uniform along the river. Thus, it was interesting to visualize the geomorphological evolution of the longitudinal river profiles. A comparative analysis was conducted between longitudinal profiles calculated for two characteristic flow rates of the Medjerda. The first flow rate $Q=80 \mathrm{~m}^{3} / \mathrm{s}$ corresponds to the flow during low water and the flow rate $Q=250 \mathrm{~m}^{3} / \mathrm{s}$ corresponds to the morphogenetic flow. In the literature, several studies have confirmed that the bank full discharge corresponds to the liquid flow for which the transported sediment discharge is maximal (Malavoi et al., 2011). The simulation results are summarized in the following (Fig. 11).

River longitudinal profile changes have interested many researchers, especially with the intention of understanding their evolution and finding the most pertinent method to eventually predict their development. From Sidi Salem dam until the Slouguia station, we observe an alternation between the two processes of erosion and deposition. It is noted that there are several factors that influence directly the river morphology, for example the secretion of low flow, the development of vegetation in the river bed, and the presence of hydraulic structure; all these factors represent obstacles to the flow and influence directly the river morphological changes. 

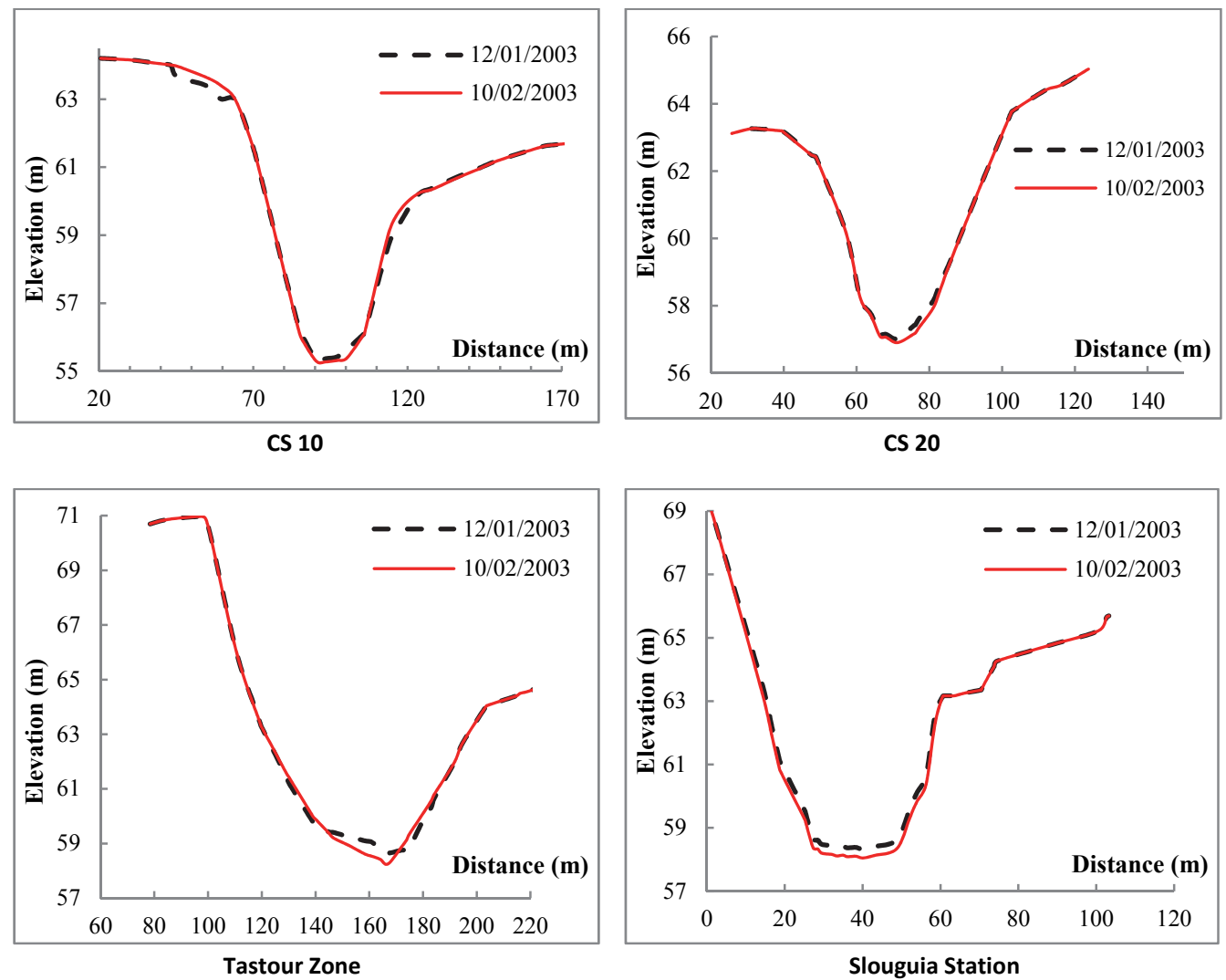

Fig. 11. Geomorphological evolution of the longitudinal profile of the Medjerda River between Sidi Salem Dam and Slouguia Station by TELEMAC 2D-SISYPHE, Flood 2003.

\section{Comparative analysis of $1 D$ and 2D river modelling}

One of the main deciding factors for model choice, including dimension, is whether the model is capable of simulating all necessary processes and complexity for the given problem (Papanicolaou et al., 2008). The model dimension choice depends largely on the treaty process; it requires special attention due to the risk and the complexity, as well as the consideration of the spatial and temporal scales of interest. One dimensional hydraulic and sediment transport models have been the easier models used for river dynamics, because of the large spatial scales and long time frames. However, two dimensional models are less commonly used due to their longer processing times, and also to the complexity of the required data. The objective of this last part is to determine the advantages and limitations of tested models. Comparative studies were conducted to analyze the obtained results. In fact, in order to get meaningful comparisons, it is evident to keep the same flow conditions for the tested model simulations (same initial condition, same boundary conditions, same roughness ...), and with the same sediment physical properties. First, we start by comparing the total sediment transport rate simulated by HEC RAS (1D) and TELEMAC 2D coupled with SISYPHE. Second, we proceeded to a comparative analysis between river longitudinal profiles predicted by both models.

\section{Variation of sediment transport rate, Flood 2003}

We compared here, the sediment transport rate simulated, by TELEMAC 2D coupled with SISYPHE and HEC RAS (1D) during the flood of 2003. The differences between the sediment transport amounts calculated by the two models are generally low, and the overall look is the same (Fig. 12).

These differences confirm the importance of the roughness parameter on the prediction of the sediment transport rate. Note that TELEMAC 2D and HEC RAS do not follow the same numerical scheme. Iterations are not conducted in the same manner as the interpolation results at the ends of meshes calculations, are not calculated in the same way. This may explain the differences between the results.

\section{Morphological evolution of cross section, Flood 2003}

In order to visualize the evolution of the cross section profile during flood, a comparison analysis was conducted between measured cross sections, and those simulated by the $1 \mathrm{D}$ and $2 \mathrm{D}$ models (Fig. 13).

The superposition of the cross sections at the same place indicates silted sections (deposition zone) and erosion sections (digging in the bottom). We note that there is a difference between simulated results with about $12 \%$. These differences are due to various factors. For example, the geometry has not been inserting with the same manner. In the 1D model, topography is defined by cross sections which generate a precise definition of the river bed but a rude definition of the floodplain (Erlich et al., 2012). In the 2D models, the mesh provides information about the river topography. In the 1D model the geometry is much smoother comparing to the $2 \mathrm{D}$ model. 


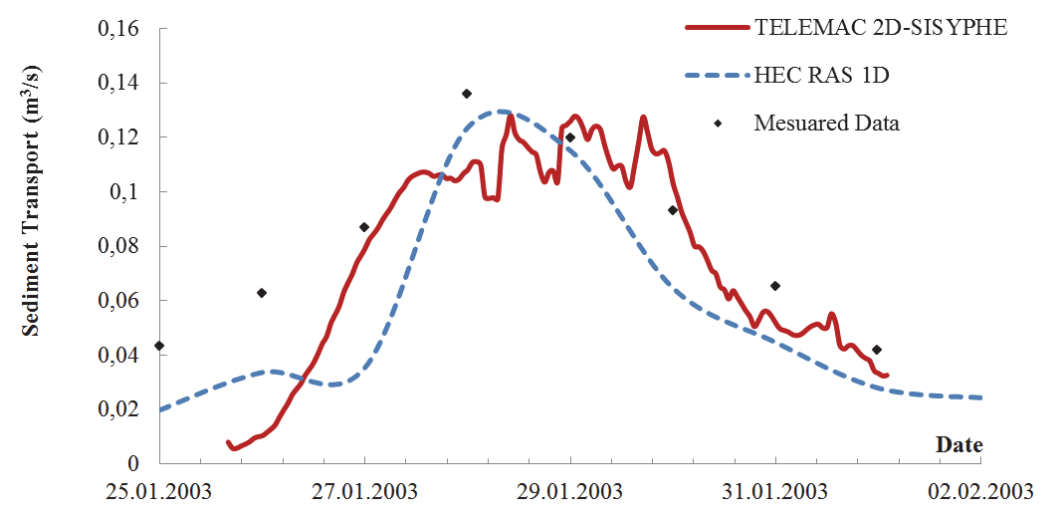

Fig. 12. Comparison of sediment transport rate calculated by 1D and 2D models at the Slouguia Station, Flood 2003.

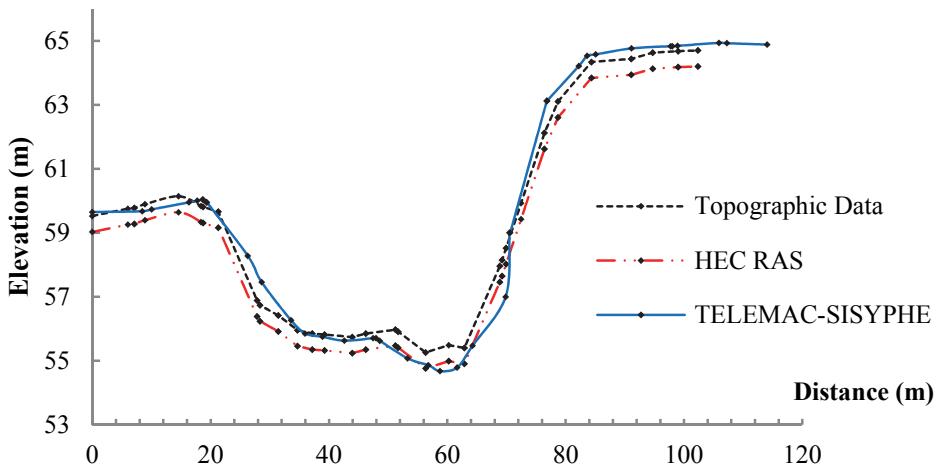

Fig. 13. Evolution of Slouguia cross section simulated by HEC RAS and TELEMAC 2D-SISYPHE, Flood 2003.

\section{CONCLUSION}

Our purpose is to develop a hydro-sedimentary model covering both the river hydrodynamic and sediment transport process. The aim is to analyse the amounts of sediment carried by the Medjerda River during the floods, and their effects on the river morphological changes. The analysis shows that the problem of sediment transport in rivers is closely related to the floods problems. Moreover, we note through the comparative analysis between $1 \mathrm{D}$ and $2 \mathrm{D}$ models that the $1 \mathrm{D}$ simulation is certainly fast to build, but the corresponding results have significant inaccuracies. However, 2D models can correct this problem but consume much more time for their implementation and simulations. The 1D models are recommended for modeling of long rivers; and they can also be used for rapid studies that do not require too much precisions. While the $2 \mathrm{D}$ models are suggested for studies that require higher precision calculations for predicting the sediment transport rates. Note that 2D models provide a complete description of the erosion and deposition rates in the banks and bottom of the river channel.

Acknowledgments. Financial support for this study was provided by a grant from the Ministry of Higher Education and Scientific Research in Tunisia. The authors wish to thank the members of HydroEco groups worked under the Institute of Fluid Mechanics of Toulouse, France.

\section{REFERENCES}

Belleudy, P., 2000. Restoring flow capacity in the Loire River bed. Hydrological Processes., 03, 1220-1233.

Bhattacharyya, K., 2011. The Lower Damodar River, India, Understanding the Human Role in Changing Fluvial Envi- ronment, Advances in Asian Human-Environmental Research.

Celik, I., Rodi, W., 1988. Modeling suspended sediment transport in non-equilibrium situations. Journal of Hydraulic Engineering., 114, 1157-1158.

Charru, F., 2006. Selection of the ripple length on a granular bed sheared by a liquid flow. Journal Physics of Fluids, 18, 121508-1.

Charru, F., Mouilleron, H., Eiff, O., 2004. Erosion and deposition of particles on a bed sheared by a viscous flow. Journal of Fluid Mech., 519, 55-80.

Diallo, D.M., 2010. Modélisation Mathématique et simulation numérique de l'hydrodynamique : cas des inondations en aval du barrage de Diama [Mathematical modeling and numerical simulation of hydrodynamics]. PhD. Thesis. Université de Franche-Comté, Laboratoire de Mathématiques de Besançon, Besançon. (In French.)

Dusty, R., 2012. One-Dimensional Versus Two-Dimensional Modeling. Ayres associates, Oakwood Hills, United States of America.

Einstein, H., 1950. The bed-load function for sediment transportation in open channel flows, Tech. Bull, U.S, Department of Agriculture, Washington, DC.

Engelund, F., Fredsoe, J., 1976. A sediment transport model for straight alluvial channels. Revue Géomorphologie Nordic Hydrology., 75, 293-306.

Erlich, M., Girard, C., David, E., 2012. Intégration du modèle hydraulique $2 \mathrm{D}$ dans la chaine de prévision des crues-éclairs en temps réel. [Integration of 2D hydraulic model for predicting flash floods in real time]. Symposium Européen, Problèmes actuels de la protection contre les inondations, Paris, Orléans. (In French.) 
Estupina, B.V., Dartus, D., Chorda, J., 2005. Prévision des crues éclair. [Flash flood Forecasting]. Géosciences de surface, Hydrologie-Hydrogéologie, Science direct, 337, 1109 1119. (In French.)

García, M., 2006. Sedimentation engineering: processes, measurements, modeling, and practice. In: Proc. World environmental and water resource congress on examining the confluence of environmental and water concerns, American Society of Civil Engineers, pp. 91-94.

Gharbi, M., Soualmia, A., 2012. Simulations des crues éclair au niveau de la haute vallée de la Medjerda. [Simulations flash floods in the upper valley of the Medjerda]. In: Deuxième Congrès Tunisien de Mécanique COTUME 2012, Sousse, Tunisie. (In French.)

Gharbi, M., Soualmia, A., 2013. Modélisation de la prévision des crues éclair au niveau du bassin versant de la Medjerda. [A model for predicting flash floods in the Medjerda watershed]. Revue de Mécanique Appliquée et Théorique, 2, 6, 585-595. (In French.)

Gharbi, M., Soualmia, A., Dartus, D., Masbernat, L., 2014a. A comparative analysis of Lajeunesse model with other used bed load models - effects on river morphological changes, Journal of Water Resources and Ocean Science, 3, 5, 61-68.

Gharbi, M., Soualmia, A., Dartus, D., Masbernat, L., 2014 b. Analysis of morphological changes in rivers. In: Proc. International conference on fluvial hydraulics: river flow, Lausanne, Switzerland, pp. 1315-1321.

Goff, J.R., Ashmore, P., 1994. Gravel transport and morphological change in braided Sunwapta River, Alberta, Canada. Earth Surface Proc and Landforms, 19, 195-212.

Goutx, D., Ladreyt, S., 2001. Hydraulique des Cours D'eau, La théorie et sa mise en pratique. [On hydraulic water courses, theory and practice]. Centre d'Etudes Techniques Maritimes Et Fluviales CETMF, pp. 1-51. (In French.)

Graf, W.H., 1984. Hydraulics of Sediment Transport. Water Resources Publications, Highlands Ranch, Colorado, USA.

Hervouet, J.M., 2007. Hydrodynamics of Free Surface Flow Modelling with the Finite Element Method. Wiley, $341 \mathrm{p}$.

Huybrechts, N., Villaret, C., Hervouet, J.M., 2010. Comparison between 2D and 3D modelling of sediment transport: application to the dune evolution. River Flow 2010.

Lajeunesse, E., Malverti, L., Charru, F., 2010. Bed load transport in turbulent flow at the grain scale: Experiments and modeling, Journal of Geophysical Research, Vol. 115.

Malavoi, J.R., Garnier, C.C., Landon, N., Recking, A., Baran, $\mathrm{Ph} ., 2011$. Elements de connaissance pour la gestion. [Elements of knowledge for management]. Office national de l'eau et des milieux aquatiques. (In French.)

Masbernat, L., Soualmia, A., Dartus, D., 2013. Solution analytique pour le calcul de la ligne d'eau dans des écoulements à surface libre à travers des enrochements. [Analytical solution for the calculation of the water line through rockfill]. In: Proc. 3ème Conférence Internationale sur l'Eau CI.EAU 2013, Alger, Algeria. (In French.)

Meyer-Peter, E., Müller, R., 1948. Formulas for bed load transport. In: Proc. 2nd Meeting of international association for hydraulic research. Int. Assoc. for Hydraulics, Stockholm, Sweden.

Papanicolaou, A.N., Elhakeem, M., Krallis, G., Prakash, S., Edinger, J., 2008. Sediment transport modeling reviewCurrent \& future developments. Journal of Hydraulic Engineering, 134, 1-14.Recking, A., 2013. An analysis of non- linearity effects on bed load transport prediction. Journal of Geophysical Research: Earth Surface, 118, 1-18.

Richards, K., Brasington, J., Hughes, F., 2002. Geomorphic dynamics of floodplains: ecological implications and a potential modeling strategy. Freshwater Biology, 47, 559-579.

Roche, P.A., Miquel, J., Gaume, E., 2012. Hydrologie quantitative, Processus, modèles et aide à la décision. [Quantitative Hydrology Processes, models and decision support]. Springer Books, Paris, France. (In French.)

Rodi, W., 1984. Turbulence Models and their Application in Hydraulics. A State-of-the-Art Review. Balkema, Leiden.

Rodier, J., Colombani, J., Claude, J., Kallel, R., 1981. Monographie hydrologique du bassin de la Medjerda. [Hydrological monograph Medjerda]. ORSTOM, Tunis, Tunisia. (In French.)

Shields, A. F., 1936. Application of similarity principles and turbulence research to bed-load movement. Mitteilungen der Preussischen Versuchsanstalt fuer Wasserbau und Schiffbau, Berlin, Germany, pp. 5-24.

Soualmia, A., Gharbi, M., 2014. Tests de simulations des crues éclair dans le bassin versant de la Medjerda Tunisie. [Flash floods simulations tests in the Medjerda watershed in Tunisia. Lebanese Science Journal, 15, 2, 13-24. (In French.)

Soualmia, A., Jouini, M., Masbernat, L., Dartus, D., 2015. An analytical model for water profile calculations in free surface flows through rockfills. Journal of Theoretical and Applied Mechanics, 53, 209-215.

Talbi, S.H., Soualmia, A., Gharbi, M., 2014. Etude de la dynamique fluviale et modélisation de la propagation de l'onde de crues au niveau de la Medjerda. [Study of river dynamics and modelling of flood wave propagation in Medjerda River]. Revue Scientifique du Ministère de l'Équipement en Tunisie, 4, 7-19. (In French.)

Tassi, P., Villaret, C., 2014. Sisyphe v6.3 User's Manual - User manual, EDFLNHE report H-P73-2010-01219

Thibault, M., 2013. Modélisation hydrodynamique couplée 1D2D du delta intérieur du fleuve Niger. PhD Thesis, Agricultural sciences, AGROCAMPUS OUEST, Rennes, France, pp. 30-50.

Van Rijn, L.C., 1993. Principles of Sediment Transport in rivers, Estuaries and Coastal Seas. Aqua Publications, Amsterdam, The Netherlands, $612 \mathrm{p}$.

Villaret, C., Hervouet, J.M., 2006. Comparaison croisée de différentes approches pour le transport sédimentaire par charriage et suspension, National Laboratory of Hydraulics and Environment. Paper presented at the IXèmes Journées Nationales Génie Civil - Génie Côtier.

Williams, G.P., Wolman, M.G., 1984. Downstream Effects of Dams on Alluvial Rivers. USGS Store, 1286, 83 p.

Wu, W., 2008. Computational River Dynamics, Sediment Laden Drainage, Betsiboka River, Madagascar. Courtesy of NASA, National Aeronautics and Space Administration, Houston, USA. Taylor \& Francis Group, London.

Wu, W., Rodi, W., Wenka, T., 2000. 3D Numerical Modeling of Flow and sediment transport in open Channels. Journal of hydraulic engineering., 126, 4-15.

Zhang, W., Yanhong, X., Yanru, W., Hong, P., 2014. Modeling sediment transport and river bed evolution in river system. Journal of Clean Energy Technologies, 2, 175-179.

Received 14 July 2015 Accepted 8 October 2015

Note: Colour version of Figures can be found in the web version of this article. 